\title{
IMPROVING TRAINING METHODS FOR AGRICULTURAL ENGINEERS
}

\author{
Alexander Pastukhov, Olga Sharaya, Nataliia Vodolazskaya, Irina Berezhnaya \\ Belgorod State Agricultural University named after V. Gorin, Russia \\ pastukhov_ag@mail.ru, sharay61@mail.ru,vnv26@bk.ru,fajzir@yandex.ru
}

\begin{abstract}
The quality of agricultural engineering education and the ability to innovation activity determine the prestige and competitiveness of universities, the possibility to attract intellectual and material resources and therefore to create the necessary conditions for training of agricultural engineering personnel. An analysis of workforce needs shows that manufacturing enterprises need specialists with a high level of practical skills. Universities are trying to cancel for this effect by implementing practical aspects of agricultural engineering education as a basic criterion for acquisition of general professional and professional competencies. The competencies of graduates of agricultural engineering direction have been determined on the basis of the analysis of existing methods of education, the modern state of technologies and equipment of the agro-industrial complex. They require strengthening of practical training in the process of education. It has been experimentally confirmed that the possibility of obtaining additional working professions during the training period not only strengthens the practical component, but also contributes to increasing interest and general motivation to improve professional skills. A training methodology has been developed. It has been tested on the disciplines "Perspective Geometry. Engineering Graphics" and "Material Science and Construction Material Technology" based on the application of practical-oriented forms of interactive training in the form of round tables, master classes and trainings. The methodology is recommended for wide application in universities of the system of agrarian education of the Russian Federation in the field of education 35.03.06 "Agricultural engineering". Research prospects are conditioned by the need to continue programs in the sections of the disciplines "Mechanics", "Metrology, Standardization and Certification", "Machine Elements and Principles of Design" and extension of the present experience within the framework of international cooperation.
\end{abstract}

Keywords: agricultural engineer, practical aspect, competencies, master class, round table, training.

\section{Introduction}

The main task of modern agrarian education is to improve the system of training and supplementary vocational education of personnel of the agro-industrial complex. It is believed that the success of European farmers in intensification of agriculture is due to their high professional level, borrowing of the best world experience, demand for scientific and technological achievements [1].

During training modern engineering personnel it is important for future specialists not only to carefully study general engineering disciplines (Descriptive Geometry, Engineering Drawing, Material Science, Technology of Structural Materials, Strength of Materials, Metrology, Standardization and Certification, Machine Elements and Design Principles), but also to have experience of certain skills and abilities for practical application of theoretical knowledge. It is necessary to be able to analyze the obtained results, to use reference literature in the work, to draw logical conclusions. This is dictated by the requirements for the modern level of training of maintenance staff for agriculture, its competence and ability to effectively use structural materials at all stages of the product life cycle from design and production to recycling. Therefore, the development and introduction of dynamic and progressive approaches and methods of teaching students and their preparation for further production activities is currently relevant [2-4]. The task is solved on the basis of deep interdisciplinary integration of the above-mentioned disciplines, which form the foundation of the future engineer with other disciplines of the basic and variable part of the curriculum into a common information and educational environment of the agrarian university.

During the training for Bachelor 's and Master 's degrees, emphasis is placed on strengthening the practical component in the Belgorod State Agricultural University [5; 6]. For this purpose, an engineering education support center has been opened. It consists of digital technologies laboratories, robotics and end-to-end design and production of machine parts. Posts for practical training have been organized and remote control center of educational resources has been built up. Center combines a set of "working posts" of the university in various production areas. And also, it allows to contact the student and his mentor directly in remote access mode and, if necessary, to make adjustments to the individual plan of practical training of the student. 
It is obviously necessary to pay considerably bigger attention to detailed studying of modern technologies and the equipment for agricultural engineers [7-9]. The increasing complexity of modern technical and technological systems, the growth of their capabilities, competition between manufacturing firms makes it necessary to design increasingly complex systems, improve their reliability, ergonomic indicators, use non-standard solutions. All this leads to the need to develop new high-performance technologies and train relevant specialists in the field of agricultural engineering. The processes of industrial development and technical education in the world are characterized by an increasing need for engineers of the new generation - developers of new technologies, who possess modern tools - mathematics, methods of modeling, informatics, management. Therefore, the role of the fundamental component in learning is increased. The modern engineer has to perfectly know computer technologies, deeply understand economic problems, expect and assess social and environmental risks and the consequences of engineering activity. It should protect natural resources, not flood the environment with waste and generally monitor the environmental situation $[6 ; 10]$.

\section{Materials and methods}

We consider working out some methods of practical-oriented training of for agricultural engineers on the example of two basic disciplines: "Descriptive Geometry. Engineering Drawing" and "Material Science.Technology of Structural Materials". In the discipline "Descriptive Geometry. Engineering Drawing" students study the graphic packages Compas-Schedule and Compas-3D. Additional courses are held for this purpose. Students receive the working profession "User of the graphic program Compas-3D" after successful finishing this course. The training process consists of task solution of the section "Engineering Drawing", namely, performance of working and assembly drawings, technological, kinematic, electrical diagrams, etc. The main reason for the long time spent is not on thinking about the task, but on the design. This problem students distract from the solution of the task and it can cause mistakes. When in graphic work in "Engineering Drawing" CAD is used, the time is reduced by about three times. It should be noted that the main thing is not only the reduction of time for execution of tasks, but also the visibility of the construction documentation. Students use CAD skills in academic year projects, diploma projects, product design and process design in production $[5 ; 7 ; 11 ; 12]$.

In the future additional trainings and master classes are organized for consolidation of knowledge. There are used additive technologies in the design of agricultural machines and technological equipment of processing plants. That all allows to apply the accumulated knowledge. Trainings are conducted according to the following scenario. The first preparatory stage is disassembling and cleaning. Research and choice of problem parts requiring additional study is carried out (Fig. 1). The second stage is micrometric and other measurements, preliminary assessment and final selection of the part. At the third stage the part in Compas-3D package is modeled, if necessary, complementing with a digital information model. The resulting model is printed using a 3D-printer. Comparative evaluation of the resulting model is done.

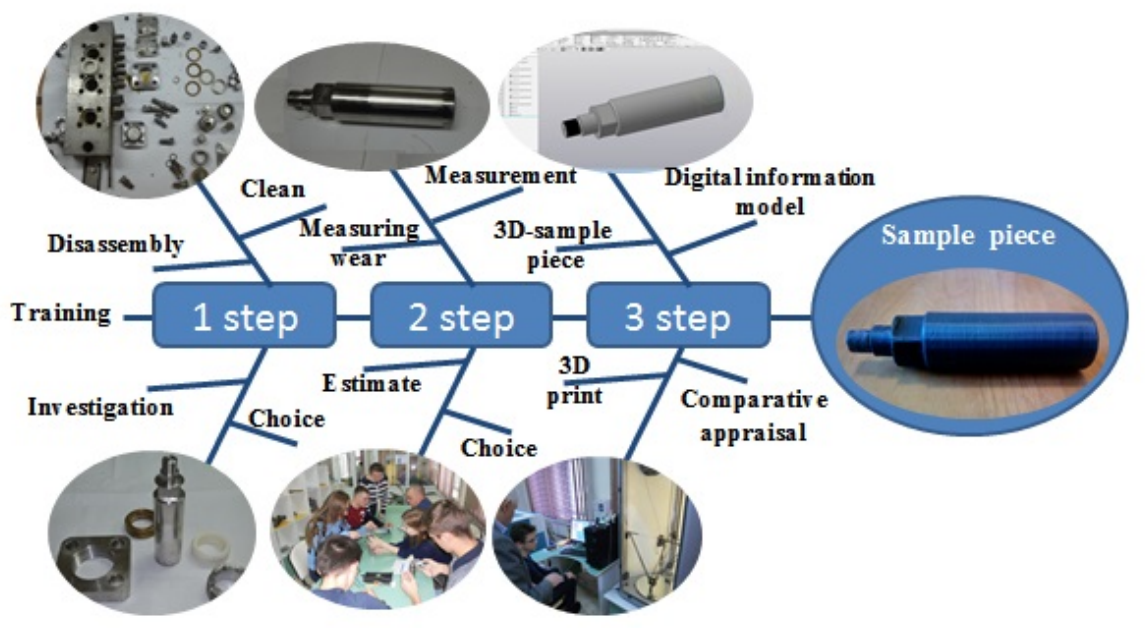

Fig. 1. Additive technology training 
The next step in end-to-end design and production is to study the basics of material science and the technology of structural materials (Fig. 2). In order to implement the practical component, master classes and trainings are held to study the microstructure of the material, determine the hardness and technology of thermal treatment processes of machine parts $[6 ; 9 ; 13]$.

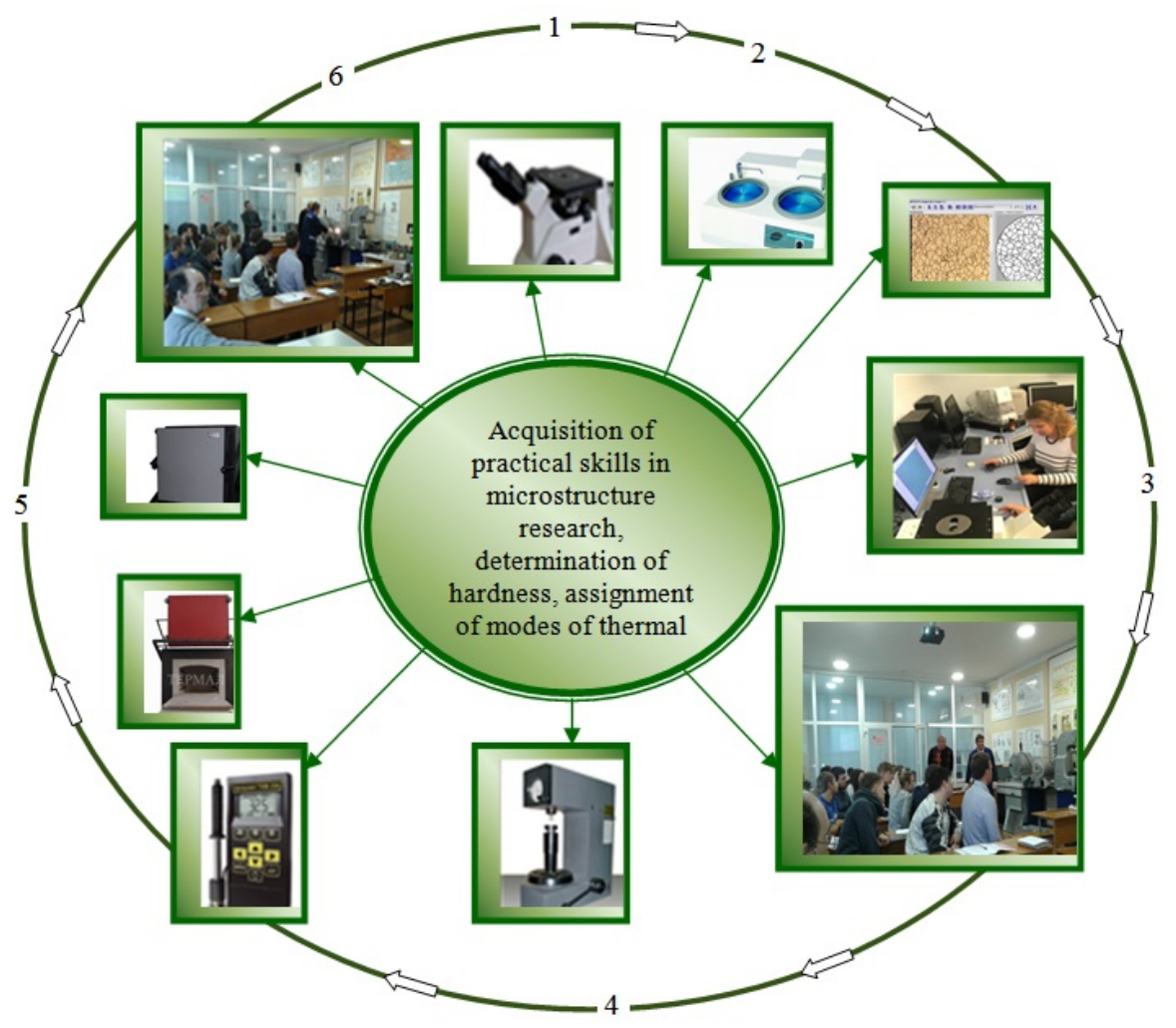

\section{Fig. 2. Master classes and equipment for practical skills in discipline "Material Science and Technology of Structural Materials" (stages 1-6)}

In the first stage of the study, it is necessary to perform the following operations: 1) to study the device, optical circuit and operation principles of the inverted metallographic microscope METAM LV 34 equipped with a digital camera MC-5;2) to acquire practical skills in tuning and working with the metallographic microscope; 3 ) to study the microstructures of the finished microslices.

In the second stage of the study: 1) to prepare microslices from the cut samples; 2) to determine the chemical composition of the etching reagent and prepare it in the metallographic sector of the laboratory for the study of structures of physical, mechanical and technological properties of materials.

In the third step: 1) to perform microstructural analysis of prepared samples using metallographic microscope METAM LV 34; 2) to determine the approximate carbon content (based on the ratio of structural components) and the possible steel grade of each sample according to reference data from the results of microanalysis.

The fourth stage involves studying the principles of operation of the instruments and the method for measuring hardness: Brynell press TSh-2M, hardness meter TP 5006 for measuring Rockwell hardness and universal portable hardness tester TKM $-359 \mathrm{M}$. In this step, it is necessary: 1) to determine the hardness of the samples in one way or another using hardness measuring instruments and record the results; 2) to compare the obtained measurement results with reference data and specify steel grades of the tested samples, taking into account the dependence of steel hardness on carbon content.

In the fifth stage: 1) to justify strengthening heat treatment - quench and temper process; 2) to set the heat treatment modes; 3 ) to make a diagram of the process of heat treatment; 4) to load the samples into the furnace and perform all the heat treatment cycles; 5) after each step, to perform hardness control measurement; 6) to compare the obtained hardness values of the tested samples with reference data.

In the sixth step: 1) to perform a microanalysis of the thermally treated samples; 2) to analyse all results obtained in the process of complex research; 3) to draw up a report on the work performed. 
Based on the results of the work the report is carried out by the student. It contains the following items: 1) photographs of microstructures and their schemes with indication and description of structural components determined during examination of steel samples in equilibrium (annealed) state; 2) approximate chemical composition (carbon content) in each microstructure analysis sample and preliminary determination of steel grade; 3) results of hardness tests and steel grade refinement; 4) assigned heat treatment modes and heat treatment programs; 5) results of tests for hardness of heattreated samples and their comparison with reference data; 6) results of microanalysis of experimental samples after heat treatment with presentation of photographs, schemes of microstructure and their description.

As a result of the comprehensive study, students acquire practical skills that form the general professional competence of the agricultural engineer. They consist in the ability to reasonably choose a material and methods of its processing to obtain properties that ensure high reliability of the part.

\section{Results and discussion}

The work is carried out in experimental studies to identify the effectiveness of practical-oriented education of students. For this purpose, data on the introduction of round tables, trainings, master classes into the educational process and the acquisition of additional working professions during the training period were summarized.

During the research period 2016-2018, 344 students were trained. 2016 and 2017 were adopted as the control period. 2018 was allocated as an experimental year. During this period round tables, trainings and master classes were held to strengthen the practical component of student education.

In 2016, 116 people were trained and 80 studied Compas-3D, which is $69.3 \%$. In 2017, 103 persons studied, including according to the 3D-Compas program - 76 people or $73.6 \%$. In 2018 pilot year, a total of 125 people were trained, including 107 or $84.6 \%$ under the Compas-3D programmer (Fig. 3).

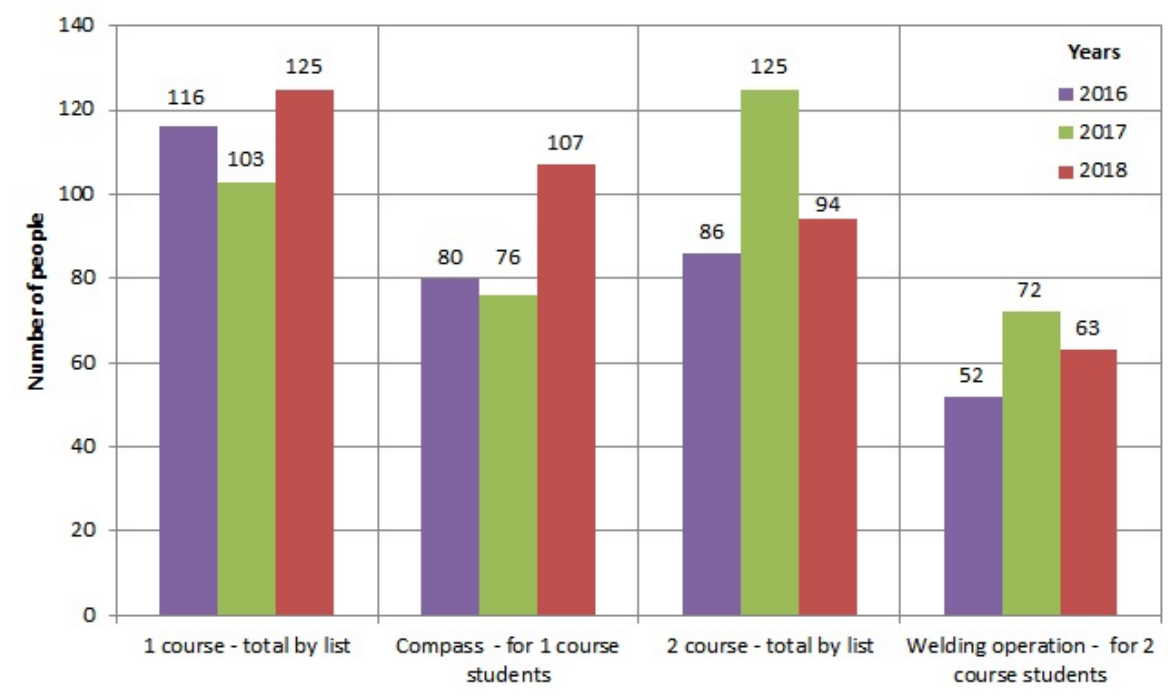

Fig. 3. Data on training of students of training direction "Agricultural engineer"

Analysis of the data shows an increase in practical interest not only in the technical specialty as a whole, but also an increase in motivation to study the discipline "Descriptive Geometry. Engineering Drawing" based on basic knowledge of the Compas-3D program (Fig. 4).

Before studying the discipline "Material Science. Technology of Structural Materials" students complete a graduate internship of obtaining primary professional skills and abilities. They have the opportunity to acquire an additional working profession "Electric welder of manual welding". During the researched period in the second year at the Faculty of Engineering 305 people were trained. In 2016 from 86 students, 52 people received an additional work profession, which is $60.5 \%$. In 2017 from 125 second-year students, 72 people or $57.6 \%$ chose to receive an additional profession. In 2018 from 94 students in the second year, 63 students or $67.0 \%$ have successfully acquired the additional working profession "Electric welder of manual welding" (Fig. 3). 
The analysis of the obtained data showed existence of increase in interest and motivation to practical training for the first year students in 2018, in comparison with control 2016 and 2017, on average for $12.75 \%$ annually, and the second-year students - on average for $5.75 \%$ (Fig. 4).

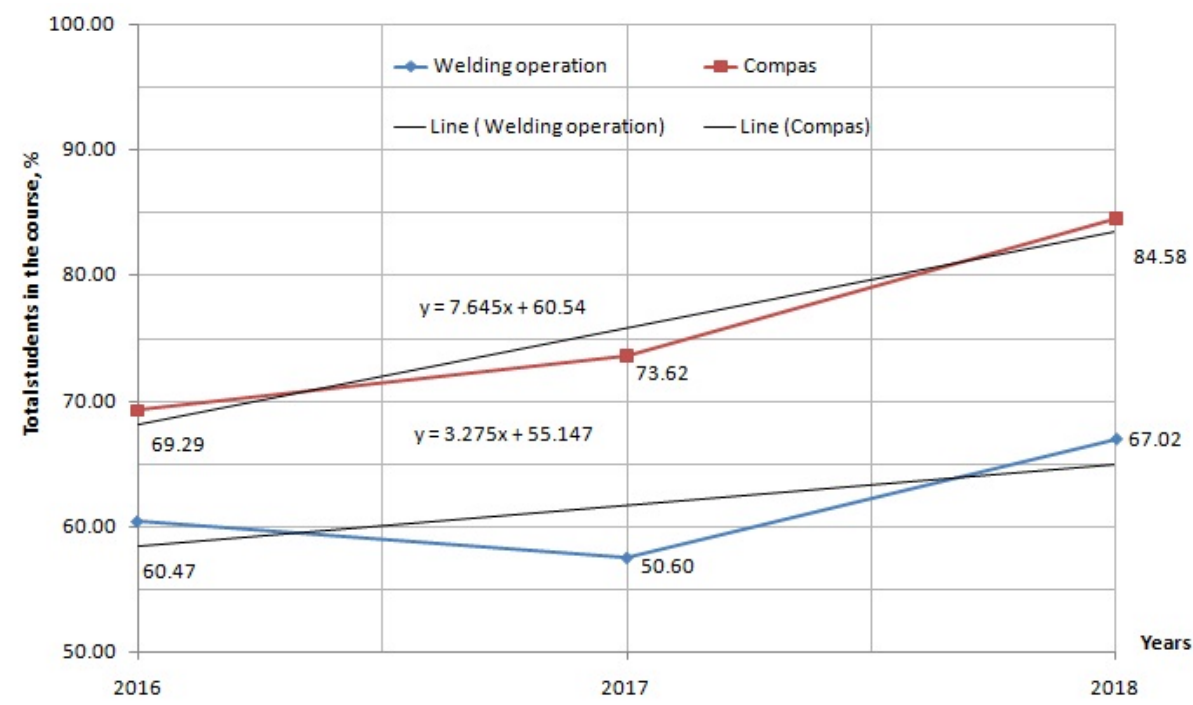

Fig. 4. Student interest and motivation trend

Implementing the tasks of the research, as a result we come to rank the sequence of acquisition of competences, starting with the discipline "Descriptive Geometry. Engineering Drawing" continuing in the development of "Material Science. Technology of Structural Materials" and in subsequent general engineering and special disciplines.

Conceptually we accept ranking in the form of a quantitative assessment by the level of importance of competences (from simple to complex) with access to complex course projects and graduate qualification work.

We hold the view of most authors that ranking the assessment of knowledge and skills is an extension of the significance of competences. And we propose to interpret ranking in terms of quantitative attractiveness of study of disciplines for students.

Summarizing the obtained data (Fig. 3, 4), it can be concluded that the improved methodology proposed by us in the experimental year 2018 contributed to the increase of interest and general motivation for practical training in students of 1 and 2 courses by an average of $9.25 \%$. It is possible to say a high degree of reliability and stability of the obtained data, because of the value of confidence of approximation (R-squared value) equal to 0.705 .

Quantitative data of observations allowed to rank the assessment of formed competences through attractiveness to study of disciplines on the basis of acquisition of additional working professions: in the first year - Compas-3D by $12.75 \%$, in the second year - electric welder manual welding - by $5.75 \%$ or on average by $9.25 \%$ annually.

Similar trends are noted in studies of other scientists in the field of engineering training of students in technical universities $[6 ; 9 ; 10 ; 11]$.

\section{Conclusions}

1. The most practical-oriented forms of interactive training organization for technical specialties are round table, training, master class.

2. Analysis of technical condition of machines and equipment of agricultural complex shows a necessity to deepen the practical component in general engineering disciplines.

3. The training method of agricultural engineers based on analysis of specific situations through simulation exercises in the forms of round table, training and master class has been improved. Interactive forms of organization and methods of holding round table, training and master class are practically tested and implemented.

4. According to the results of the research, it was found that attractiveness to study disciplines on the 
basis of acquisition of additional working professions increased on average by $9.25 \%$. The work carried out points to the need to improve the methodology of training agricultural engineers with extension to subsequent general engineering and specialized disciplines in order to ensure an endto-end multilevel cycle of acquisition of practical skills and abilities and dissemination of the present experience in the framework of international cooperation.

\section{Acknowledgements}

The studies were carried out within the framework of the grant of the Ministry of Agriculture of the Russian Federation on the topic "Improvement of educational methods for training agriculture engineers taking into account the practical component" N 4.7.35 in 2018.

\section{References}

[1] Murzagaliyeva A., Jugembayeva B. Readiness for innovative activity as important professional competence of new generation engineer. Engineering for rural development. Latvia University of Life Sciences and Technologies, Jelgava, 2019, Vol. 18, pp. 1899-1902.

[2] Водолазская Н.В. Особенности маркетинговых стратегий в сфере современных образовательных услуг (Features of marketing strategies in the sphere of modern learning services). Eastern European Journal of Advanced Technologies, 2012, No 1/13(55), pp. 27-29. (In Russian).

[3] Klimova S., Kondykov A., Mertsalov E. Algorithm for the formation of personnel potential in the scientific and educational sector of the agrarian sector based on cluster and pedagogical approaches // IOP conference series: Earth and Environmental Science. 2019. 274. P. 012088

[4] Vodolazskaya N.V., Minasyan A.G., Pastukhov A.G., Sharaya O.A. The electronic environment of modern higher education - m-learning basis. Proceedings of the International Mobile Learning Festival 2015: Mobile Learning, MOOCs and 21st Century learning, Hong Kong SAR China, 2015, pp. 712-722.

[5] Шарая О.А., Водолазская Н.В., Пастухов А.Г., Стребков С.В., Бережная И.Ш. Практическая составляющая технического образования - основа формирования агроинженера (Practical component of technical education - the basis of formation of the agroengineer). Standards and monitoring in education, 2018, No. 5'2018 (122), pp. 41-46. (In Russian).

[6] Тараховский А.Ю. Использование среды Moodle в контексте смешанного обучения, студентов технических специальностей (Using the Moodle Environment in the context of mixed training of technical students). Modern problems of machine theory, 2019, No 8, pp. 2527. (In Russian).

[7] Yunusbaev N.M., Gabitov I.I., Farhshatov M.N., ect. Perspective method of restoration of autotractor parts by electrocontact welding of powder materials in the magnetic field. Tribology in industry, 2019, Vol. 41, No. 1, pp. 115-125.

[8] Kvon S.S., Kulikov V.Y., Filippova T.S. et al. Using high-chromium iron as material for production of the equipping components of mine shafts. Metalurgija (Zagreb, Croatia), 2016, Vol. 55, No. 2, pp. 206-208.

[9] Vitols G., Arhipova I., Paura L. Engineering study program compliance evaluation to guidelines for software engineering curriculum. Engineering for rural development. Latvia University of Life Sciences and Technologies, Jelgava, 2019, Vol. 18, pp. 1910-1914.

[10] Хамидулин В.С. Модернизация модели проектно-ориентированного обучения в вузе (Modernization of model of project-oriented training in higher education institution). Higher education in Russia, 2020, No. 1, pp. 135-149. (In Russian).

[11] De Graaff E., Kolmos A. Characteristics of Problem-Based Learning. International Journal of Engineering Education, 2003, Vol. 19 (5), pp. 657-662.

[12] Issagulov A.Z., Kvon S.S., Kulikov V.Y., Kovalyova T. Studying intermetallic phase of Ni-Cr superalloy after thermal processing. Metalurgija (Zagreb, Croatia), 2017, Vol. 56, No. 3-4, pp. 379-381.

[13] Hanney R., Savin-Baden M. The Problem of Projects: Understanding the Theoretical Underpinnings of Project-Led PBL. London Review of Education, 2013, Vol. 11(1), pp. 7-19. 